\title{
The quadriceps angle and the incidence of knee injury in Indian long-distance runners
}

\author{
T Puckree (BSc Physio, MS (Exercise Science), MEd, PhD (Exercise Physiology)) ${ }^{1}$ \\ A Govender (B Physio) $)^{2}$ \\ K Govender (B Physio) ${ }^{2}$ \\ P Naidoo (B Physio) $)^{2}$ \\ ${ }^{1}$ Department of Physiotherapy, University of KwaZulu-Natal, Durban, and School of Physiotherapy, Sport Science and Optometry, University \\ of KwaZulu-Natal, Westville Campus, Durban \\ ${ }^{2}$ Final-year physiotherapy students (at time of the study), Department of Physiotherapy, University KwaZulu-Natal, Durban
}

\begin{abstract}
Objective. To investigate the incidence of knee injuries in runners and to determine the proportion of injuries involving abnormal quadriceps (Q)-angles.

Design. One hundred male Indian runners between the ages of 25 and 65 years from 5 athletic clubs in Durban volunteered to participate in the study. The $\mathrm{Q}$-angle was measured using a goniometer. Other relevant information was obtained using a validated questionnaire. The data were analysed by comparing measured Q-angles with 'normal' values of $Q$-angles obtained from the literature. A paired $t$-test at a probability of 0.05 was used.
\end{abstract}

Setting. Data were collected at club meetings.

Main outcome measure. The primary outcome of the study was to determine the proportion of runners with abnormal $\mathrm{Q}$-angles. Thereafter the rate of knee injuries in runners with abnormal $\mathrm{Q}$-angles was determined.

Results. Data from 88 runners were usable. Fifty-one per cent of the runners sustained knee injuries. Fifty-eight per cent of the sample had abnormal Q-angles. Sixty-seven per cent of the runners with abnormal Q-angles sustained knee injuries.

Conclusion. More runners with abnormal Q-angles sustained knee injuries. There is a need to determine reference values for $\mathrm{Q}$-angles for the South African population, the proportion of the population that present with abnormal Q-angles, and the reasons for this.

\section{CORRESPONDENCE:}

\section{T Puckree}

Department of Physiotherapy

University of KwaZulu-Natal

Private Bag X54001

Durban

4000

Tel: 031-260 7977/7817

Fax: 031-260 8106

E-mail: puckreet@ukzn.ac.za

\section{Introduction}

Running, whether for recreation, fitness or professionally, has gained popularity all over the world. Associated with this relatively inexpensive and popular code of sport, is the risk of injury. ${ }^{6,13-15}$ It is clear that injuries sustained during running can be attributed to a wide range of causes and many of these have been the subject of investigation. ${ }^{11,13-15,19}$ Some studies have associated the risk of knee injury with the quadriceps (Q)-angle. ${ }^{9,12,19}$ Van Mechelen ${ }^{19}$ has suggested that during running there is excessive use of the extensor mechanism of the knee resulting in an imbalance of the components of the quadriceps muscle. A stronger vastus lateralis pulls the patella laterally resulting in a larger Q-angle, while a stronger vastus medialis pulls the patella medially resulting in a smaller $\mathrm{Q}$-angle. ${ }^{2,4,8}$ Therefore the $\mathrm{Q}$-angle is an indicator of the imbalance between components of the quadriceps muscle. The $Q$-angle is the acute angle that is formed when the line connecting the anterior superior iliac spine (ASIS) and the midpoint of the patella intersects with the line connecting the tibial tubercle to the midpoint of the patella. The normal range for this angle in males is $10-22$ degrees. $7,8,17,19$ Some studies $^{12,15,18,19}$ have found an association between running injuries and malalignment of the lower limb reflected in the Q-angle. In South Africa, no studies have reported on $\mathrm{Q}$-angles or the association between running injuries and the $\mathrm{Q}$-angle. Therefore the purpose of the present study was to investigate the association between the Q-angle and the prevalence of knee injuries in long-distance runners in Durban, South Africa.

\section{Methods}

A list of long-distance Indian male runners aged between 25 and 65 years registered with 5 athletic clubs in Durban was obtained. From this list a random sample of 100 male runners was selected to participate in the study (20 subjects were chosen randomly from each of the 5 clubs). Subjects gave fully informed voluntary consent. Due to ethnic and gender differences in body stature and skeletal alignment, ${ }^{16}$ participation was limited to South African males of Indian descent. Since Durban is home to the majority of this population group in South Africa, recruitment of subjects was facilitated. A per- 
spex goniometer routinely used by physiotherapists was used to measure the $\mathrm{Q}$-angle as described below. Three readings were taken successively, 1 minute apart while the subject assumed the supine position, to ensure test-retest reliability. A questionnaire with open and closed-ended questions was used to capture information relating to knee injuries and demographic details of the participants. The content validity of the questionnaire was checked through a pilot study using 5 non-participating runners. All subjects were accessed either at club meetings, time trials or during races. Each participant signed a fully informed consent form. The study received ethical approval from the University of Durban-Westville Ethics Committee.

\section{Measurement of the Q-angle}

The Q-angle was measured according to the method described by Livingston and Spaulding. ${ }^{10}$ The subject lay supine on a plinth with the foot position standardised using a foot board. The anterior superior iliac spine (ASIS), the centre of the patella and the tibial tuberosity were marked using a kohl pencil. The centre of the goniometer was placed on the centre of the patella (found by intersecting width and length lines). The stationary arm of the goniometer was aligned with the ASIS and the movable arm was aligned with the tibial tuberosity. A third vertical line which extended from the tibial tuberosity along the femur allowed the formation of an angle. The acute angle formed was defined as the $\mathrm{Q}$-angle. Three readings were taken for each subject by one investigator. The mean error was less than $0.01 \%$.

\section{Data analysis}

The average of 3 readings for each subject was used in the data analysis. These readings were compared with reference $\mathrm{Q}$-angles for male subjects as obtained from the literature. ${ }^{17}$ A chi-square test was used to compare injured and uninjured runners with abnormal and normal $\mathrm{Q}$-angles, with $p<0.05$. The data from the questionnaire were used to categorise the runners into 2 groups with and without knee injuries. Knee injury in this study was defined as an injury to the knee requiring medical or other attention. Each of these groups was stratified based on normal and abnormal Q-angles, age, running experience, and knee pain. Knee pain was defined as a reported perception of pain in the knee by the participants.

\section{Results}

The participation rate was $100 \%$. Data analysis was carried out on the data from $88 \%$ of the participants. Twelve per cent were excluded due to arthritis, deformities, and history of fractures.

Incidence of knee injuries was 51\% (45 of the 88 runners). As shown in Table I, 51 (58\%) of the 88 runners had abnormal Q-angles. Sixty-seven per cent of these runners sustained knee injuries compared with $30 \%$ of runners whose $\mathrm{Q}$-angles were normal $(p<0.05)$. Seventy-six per cent of the 34 injured runners with abnormal Q-angles were between 36 and 60 years of age compared with $18 \%$ of the 11 injured runners with normal $\mathrm{Q}$-angles $(p<0.05)$.

Table I also shows that the proportion of injured runners $(67 \%)$ was as high as the prevalence of abnormal Q-angles $(58 \%)(p<0.05)$.

Training history did not affect the proportion of runners who were injured. Sixty-three per cent of all the runners complained of knee pain. One hundred per cent of those with abnormal Q-angles and only $11 \%$ of those with normal Qangles complained of knee pain. The majority of those with knee pain and abnormal Q-angles complained of anterior knee pain $(57 \%)$.

\section{Discussion}

The incidence of knee injuries in long-distance runners in the population under study was high and similar to that reported by van Mechelen. ${ }^{19}$ James $^{6}$ reported that the majority of running injuries occur at the knee. The Q-angle has been found to influence lower extremity kinematics. ${ }^{5}$ Alteration in the $\mathrm{Q}$-angle changes the pattern of stress experienced by the patella cartilage ${ }^{19}$ and thereby is the precursor to many knee injuries. Imbalance of components of the quadriceps muscle, which insert on the patella can displace the patella, thereby effectively altering the Q-angle. ${ }^{4}$ Hart et al. ${ }^{3}$ found that fatigue of the lumbar paraspinal muscles reduced vastus lateralis activation. Noakes ${ }^{14}$ suggested that a pronated foot due to hypermobile feet could be implicated in knee problems. Because the $\mathrm{Q}$-angle is formed between the vectors for the combined pull of the quadriceps femoris and the patella tendon, ${ }^{9}$ the strength of the quadriceps muscle is important. Our findings of significantly more injuries in persons with abnormal Q-angles concur with those reported by Lysholm and Wiklander. ${ }^{11}$ These researchers reported that $40 \%$ of knee injuries that occurred in running were caused by malalignment of the lower limb and in their case increased $\mathrm{Q}$-angles. In those runners aged 36 - 60 with abnormal Q-angles, the

TABLE I. Number and percentage of injured and uninjured runners with abnormal and normal Q-angles by age group

\begin{tabular}{|c|c|c|c|c|c|c|c|}
\hline \multirow[b]{2}{*}{ Age (years) } & \multicolumn{3}{|c|}{ Abnormal Q-angle } & \multicolumn{3}{|c|}{ Normal Q-angle } & \multirow[b]{2}{*}{ Total } \\
\hline & Injured & Uninjured & Total & Injured & Uninjured & Total & \\
\hline $25-35$ & $6(46 \%)$ & $7(54 \%)$ & $13(25 \%)$ & $2(5 \%)$ & $6(16 \%)$ & $8(22 \%)$ & \\
\hline $36-60$ & $28(76 \%)$ & $9(24 \%)$ & $37(73 \%)$ & $2(18 \%)$ & $17(46 \%)$ & $19(51 \%)$ & \\
\hline $60+$ & $0(0 \%)$ & $1(100 \%)$ & $1(2 \%)$ & $7(19 \%)$ & $3(8 \%)$ & $10(27 \%)$ & \\
\hline Total & $34(67 \%)$ & 17 (33\%) & 51 (58\%) & $11(30 \%)$ & $26(70 \%)$ & $37(42 \%)$ & 88 \\
\hline
\end{tabular}


incidence of knee injuries was higher than among those with normal Q-angles. Brill and Macera ${ }^{1}$ and van Mechelen ${ }^{19}$ suggest that normal younger-aged male runners train at higher speeds than their older counterparts thereby not allowing sufficient time for the adaptive process required in the musculoskeletal system. The age range of our runners with highest injury rate was $36-60$. This age group is not young. A similar trend was observed for the younger age group, i.e. those between 25 and 35 years of age. Muscular factors resulting in malalignment may contribute to running-related knee injuries. Noble et al. ${ }^{16}$ suggest that the size and shape of the human femur vary with gender, age, stature and ethnic background of the individual. The sample in this study included Indian males over a range of ages. Although the percentage of runners with abnormal Q-angles was high, one cannot assume that this population group is different from other racial groups in this country, since no data exist to suggest this.

Although the data from this study on Indian male runners concurs with that from other studies, ${ }^{10,19}$ there is a need for more research in this area using samples from different race groups and genders in South Africa.

\section{Conclusion}

In this sample, abnormal Q-angles were directly proportional to the incidence of knee injuries in long-distance runners. There is a need to first of all determine reference values for Q-angles for the South African population by race, gender and age. The major determinants of abnormal Q-angles can then be determined and rehabilitative strategies put in place.

\section{RefERENCES}

1. Brill PA, Macera $C A$. The influence of running patterns on running injuries. Sports Med 1995; 20: 365-8.

2. Grelsamer GP, Weinstein $\mathrm{CH}$. Applied biomechanics of the patella. Clin Orthop 2001; 389: 9-14.

3. Hart JM, Fritz JM, Kerrigan DC, Saliba EN, Gansneder BM, Ingersoll CD. Reduced quadriceps activation after lumbar paraspinal fatiguing exercise. Journal of Athletic Training 2006; 41(1): 79-86.

4. Hehne HJ. Biomechanics of the patellofemoral joint and its clinical relevance. Clin Orthop 1990; 258:73-85.

5. Heiderscheit B, Hamill J, Caldwell GE. Influence of $Q$ angle on lower extremity running kinematics. J Orthop Sports Phys Ther 2000; 5: 271-8.

6. James SL. Running injuries to the knee. J Am Acad Orthop Surg 1995; 8:309- 18.

7. Juhn MS. Patellofemoral pain syndrome: A review and guidelines for treatment. Am Fam Physician 1999; 60: 2012-22.

8. Latinghouse $\mathrm{LH}$, Trimble $\mathrm{MH}$. Effects of isometric activation on the Q-angle in women before and after quadriceps exercise. J Orthop Sports Phys Ther 2000; 30: 211-6

9. Livingston LA. The quadriceps angle: A review of the literature. J Orthop Sports Phys Ther 1998; 28:105-9.

10. Livingston LA, Spaulding SJ. Measurement of the $Q$-angle using standardized foot positions. Journal of Athletic Training 2002; 37:252-5.

11. Lysholm J, Wilkander J. Injuries in runners. Am J Sports Med 1987; 15:168-71.

12. Macera CA. Lower extremity injuries in runners. Sports Med 1992; 13(1): 50-7.

13. Messier SP, Davis SE, Curl WW, Lowery RB, Pack RJ. Etiologic factors associated with patellofemoral pain in runners. Med Sci Sports Exerc 1991; 23: 1008-15.

14. Noakes T. The Lore of Running. Leeds, UK: Human Kinetics, 2003.

15. Nobel C. The Pfizer Manual of Sports Injuries. Cape Town: Medical Tribune Publication, 1997: 40-63.

16. Noble PC, Box GG, Kamarie E. The effects of aging on the shape of the proximal femur. Clin Orthop 1995; 3163: 1-44.

17. Reider B, Marshall JL, Warren RF. Clinical characteristics of patella disorders in young athletes. Am J Sports Med 1998; 18:220-7.

18. Taimela S, Kujalo. M, Oesterman K. Intrinsic risk and athletic injuries. Sports Med 1990; 9:205-15.

19. Van Mechelen W. Running injuries: A review of the epidemiological literature. Sports Med 1992; 14: 320-35. 